\title{
SUBTERRANEAN STREET PLANNING
}

\author{
By George S. Webster,
}

Chief Engineer and Surveyor, Philadelphia.

Although much careful study has been given by trained experts to the preparation of plans for the rebuilding and extension of large cities and the laying out of new towns, and to the development and improvement of street systems so as to provide for present and future surface traffic and to best serve the convenience, health and welfare of the people, but little thought has been given to the subterranean street. In only a very few of our large cities has any attempt been made to plan subterranean streets or to chart the structures which they contain.

Underground circulation is as necessary to modern municipal life as surface circulation and the problems involved in its installation and maintenance have become exceedingly complex and difficult as the demand for such service has increased. Surface traffic may be entirely shifted off of a street temporarily, in case of an emergency, without inflicting any great hardship, but underground service, once installed becomes permanent, and any derangement or interference with it oftentimes seriously affects large areas.

But few of the great multitude of people who traverse the principal thoroughfares in the congested parts of any large city have any conception of the great network of structures which have been laid at an enormous cost under the street surface, all of which are necessary to provide the service so essential to meet the demands of modern business and modern methods of living.

To consider the importance of subterranean streets properly, it is necessary to have a clear understanding of their functions and of what they are required to care for. The structures which they contain may be classified under the following heads:

1. Water pipes, sewers, gas pipes, electrical conduits, steam and hot water pipes, pneumatic tubes, refrigerating pipes and an inconceivable number of other structures of a similar character which will be required in the future.

2. Subway galleries for pipes and conduits. 
3. Vaults under the sidewalks.

4. Subways for passenger railway traffic.

5. Tunnels crossing the subterranean streets.

6. Subterranean freight service, to connect with railroad terminals, business houses and industrial establishments.

In the growth of a modern city the number and character of underground structures are constantly increasing and changing and it is probable that the future will see the present ones supplemented by others now scarcely thought of. Therefore, in the placing of sewers, water pipes, gas pipes, electrical conduits, pneumatic tubes, refrigerating pipes and other structures necessary for present service, it is important that the available width of the street be utilized to the best possible advantage. This can only be accomplished through municipal control by some official body with absolute power to finally approve the location of every sub-surface structure and to see that each is placed in the space assigned to it. All structures occupying a street longitudinally should be laid parallel with the street lines; where this is done and accurate records kept showing the location, size and depth of all conduits and pipes, maximum economy of space will be obtained and the location for new structures can be determined with accuracy, so that there will be a minimum disturbance of the street surface. Where the records are platted on large scale maps and each structure indicated by a conventional sign, all future planning for the subterranean street is greatly facilitated.

The lack of records leads to great confusion when new services are to be laid. This is especially true when large main sewers are to be constructed or a system of railway subways installed. In such cases, before contract drawings can be completed or intelligent estimates of cost prepared, it is necessary to make at great expense deep excavations across the entire width of the street at intervals of from 100 to 200 feet along the line of the proposed improvement, to obtain information as to the obstacles that will be encountered. Such excavations in a busy traffic street as a preliminary and frequently made months in advance of the actual construction, are a great inconvenience and annoyance to the public. In many leading cities no department of the municipal government has information as to the number and character of the structures laid in its subterranean streets. Philadelphia has been keeping records of its underground works since 1884 and now has a complete system of plans made on a 
large scale, on which all structures are recorded; the cost of preparing these plans and of maintaining a corps of draftsmen to keep them up to date is more than met by the charges made to public service companies desiring plans and information to aid in determining locations for new structures.

\section{Subway Galleries for Pipes and Conduits}

The breaking of streets for the construction of, or repairs to underground works is one of the greatest obstacles to their economic construction and upkeep and earnest efforts have been made by city officials to reduce this breaking to a minimum by the adoption of stringent regulations. In Philadelphia the board of highway supervisors refuses to grant permits to open newly paved streets within five years after the paving is laid; Cincinnati has a similar regulation, covering a period of three years, and in both cities provision is made to notify in advance all city departments, public service corporations and abutting property owners of the intention to improve the street, so as to give them opportunity to lay or renew underground structures as may be required, yet with all these precautions it is occasionally necessary to tear up the street surface to repair leaks and breaks and to make emergency connections.

The construction of subway galleries to accommodate many of the pipes and conduits would be of great advantage in preventing the opening of the street surface and its attendant interference with the public comfort and convenience. The building of such galleries has never been undertaken to any extent except in Paris and London. The sewers are used to carry many service pipes and conduits in Paris and about $81 / 2$ miles of galleries have been constructed in the newly laid out streets of London. In other cities on account of the cost of building galleries in streets already improved and the re-locating of the underground structures in them, municipal authorities have concluded that the expense was not warranted.

Elaborate plans were prepared for subway galleries of this kind at the time the passenger railway subways were constructed in lower Broadway, New York; and later in Washington street, Boston, and it is to be regretted that the work was never carried out. In the city of Montreal at the present time an extensive system of municipal conduits, for wires only, is being placed under the center of 
each sidewalk, cutting off all building vaults and restoring to the city the space outside of the conduits for future structures.

Subway galleries should be constructed in newly laid out highways, through densely built-up portions of the city; they should be owned and controlled by the municipality and the public service companies should be required to occupy them with their service lines; if built while the street is being constructed and before the underground structures are laid, the cost would not be prohibitive and the rentals obtained from the public service companies would no doubt largely pay the interest and sinking fund charges on the cost of construction.

\section{Vaults Under Sidewalks}

In the centers of intense activity in large cities, particularly along the important business streets upon which high buildings, department stores and office buildings have been erected and on which traffic is congested, many vaults have been constructed which extend under and out into the highway generally the full width of the sidewalk. These vaults are in many cases practically an extension of the basement of the building into public property and are frequently used as boiler rooms from which hot air is ejected through gratings in the sidewalk to the great discomfort of pedestrians using the street. In other cases, safe deposit vaults, restaurants and barber shops occupy the vaulted space-the property owner does not secure from the city a fee simple title to the ground, but only a permit, which is conditioned upon the city having the right to repossess itself of the space occupied at any time when the public good. demands it.

These obstructions are a severe tax upon the cross-section and the capacity of the subterranean street to provide space for structures which are necessary for the general public service, and in order to retain for the public the full advantage of the space beneath the street, it will be necessary for large cities, in their business centers and along the line of main traffic thoroughfares, to refuse to grant permits for, or to allow the placing of, any obstructions either on or beneath the surface of a public highway.

Action to regain surface space on streets was taken by the municipal authorities in New York City within the past two years, and property owners on Fifth avenue and other streets in the congested 
sections were required to remove all encroachments and obstructions from the legally opened sidewalk, in order that the public might recover the free use of the portions of the street occupied for private use; similar action may become necessary to regain space occupied by vaults and other underground rooms and the confusion and conflict with owners would be avoided if such occupation was entirely prohibited.

\section{Subways for Passenger Railway Traffic}

The increase in the urban population of the United States has been much more rapid than in the rural districts, or in the country as a whole. At the close of the revolutionary war only about 3 per cent of the total population lived in what might be called cities. Today the urban population comprises 46.3 per cent of the total population. The great tendency in all our large cities, especially in America, to concentrate business activity has demonstrated the total inadequacy of the street surface to supply space to meet the problems of passenger transportation. It is therefore found necessary to provide passenger subways or elevated railroads to give the people rapid and cheap facilities for passing back and forth between their homes and places of business or from one section of the city to another.

The building of elevated railroads requires the placing of columns in the street and of heavy foundations into the subterranean street, which greatly reduces its capacity for carrying other structures, and where passenger railway subways are constructed the areas required for the subway and the requisite stations are so great that almost the entire available cross-section of the subterranean street is occupied, making it necessary to remove at great cost all or a large number of other structures to adjacent streets.

The building of railway subways has brought a new use for the subterranean street and to meet its demands an exhaustive study is required not only of the underground conditions but of the surface conditions, for the building of subways on narrow streets lined on both sides with costly buildings requires the underpinning of these buildings and entails very expensive construction work and damage to adjacent property. This in some localities may be avoided by opening a new wide street or the widening of an existing street a short distance from the main traffic highway where property is of less value. 
Such a new avenue should be of sufficient width to admit of the subway being constructed in the center thereof and avoid underpinning and damage to property. It is probable that in some cases such new street may be acquired and the subway constructed at approximately the same cost as the subway in a narrow street, congested with surface travel and lined with high buildings. In addition, great advantage would accrue to the public by having this new side avenue to supplement its street system; relief would be given to highway congestion on the adjacent streets and opportunity would be furnished to extend the business areas along new lines.

The demands of subways upon the subterranean streets are such that where a traffic line in one street crosses or connects with that in another the intersection must be enlarged to permit such crossing or connection; such enlargement of intersections should also be applied wherever possible to the street surface so as to relieve vehicular congestion. The uses of the surface and subterranean areas are so closely co-related in respect to the needs of circulation that they should be studied and planned together with due regard for the probable future usefulness of each.

\section{Tunnels Crossing Subterranean Streets}

Tunnels constructed by private interests to cross subterranean streets to connect the basement stories of buildings on opposite sides result in blockading the streets to such an extent as almost to prevent their proper use for public purposes, and is an occupation of the streets which should not be permitted unless the tunnel is placed at such a depth as to carry it under the structures laid longitudinally and required to conserve the public welfare.

Where tunnels are required for the convenience of passengers who wish to cross from one subway platform to another, the plans prepared for such passageways should make ample provision for all the structures which are to be placed in the subterranean street, and the locations made subservient to the present and future requirements of general public service circulation.

\section{Subterranean Freight Service}

The congestion of pedestrian and vehicular travel on the surface of the important business streets of a great city can unques- 
tionably be greatly relieved by providing for the transportation of merchandise and freight to and from the railroad terminals, manufactories and business houses through freight subways placed in the subterranean street. Also the health and comfort of the people require that the waste from houses and much of the débris from building operations be removed without being carried over the street surface; freight tunnels constructed in the subterranean street may be utilized for both the above purposes. Such tunnels have been constructed in Chicago and placed at such a depth below the surface of the street as not to interfere with other sub-surface structures; they connect with the sub-basements of the large business establishments, railroad terminals, post offices and manufacturing establishments, and much good has been accomplished and relief given to the surface of the street, but unfortunately the size of the tunnels in Chicago is too small to permit of the shipment of freight in bulk; hence the improvement has not been profitable, but it has demonstrated that tunnels of sufficient capacity to carry freight without breaking the package can be successfully operated and that they will result in the economical handling of freight and the giving of great relief to the congestion on the street surface.

In order to obtain the maximum utilization of streets in which passenger subways are constructed, it has been suggested that subterranean sidewalks be built connecting the various subway station platforms in such a manner as to make a continuous sidewalk on both sides of the railway tracks and adjacent to the buildings on either side of the street. Fronting on these sidewalks, stores may be opened in the basement of buildings and bulk windows constructed. Such improvements do not appear to be desirable, as they would further increase the number of people daily using the street and would encourage the transaction of business under the surface where ventilation would be poor and unhealthy conditions liable to obtain. The welfare of the people can be much better served by providing other localities for commerce and trade on the surface of the streets and thus extend and make available a much larger area for business activity.

It is highly desirable that all ugly and objectionable traffic and service should be put under the street and that it shall be done in such a way that the fewest possible number of people will be required to conduct it, and it is in the interest of the conservation of the public 
health to put nothing under the street which attracts or requires a large number of people to pass any considerable time there.

People interested in city planning have suggested that in the rebuilding of the congested parts of a city the two-story street be adopted, so designed that all pedestrian travel and light traffic would be upon the surface and all freight transportation in the street beneath,- the surface street to be constructed like a bridge roadway and never interfered with except for the proper upkeep and repairs, and in the subterranean street beneath provisions to be made for freight transportation and the whole system of pipes and conduits required to supply the public with the necessities and conveniences of modern urban life.

When one first reads Eugene Hénard's description of "The Cities of the Future," he feels that Mr. Hénard has drawn largely upon his imagination, but upon careful study of the conditions which now exist on the surface and in the subterranean streets and the requirements that will be placed upon these streets in the future by the continued concentration of people in the business centers of our cities, it will be realized that his ideals are not greatly overdrawn.

If healthy conditions are to be maintained and the comfort and convenience of the citizens conserved, it will be necessary to provide for carrying many more of those services which are essential to the comforts of life, in the subterranean streets. The advent of the electrically operated vacuum cleaner, now coming into general use, may result in the placing of conduits in the streets to carry this waste to a central disposal plant. The garbage and ashes from the homes of the people may be removed in a sanitary manner through subterranean channels and the garbage cart and ash wagon may disappear from the surface of our streets. The use of pneumatic tubes, steam heating and refrigerating pipes will be multiplied, and to provide for these added services as careful planning will be required for the subterranean street system as is now given to the surface street system; and every town planner in preparing plans for laying out new main thoroughfares and the development of street intersections must consider the requirements of the subterranean street and include it in his studies as an essential part of the city plan. 